\title{
Comparison of Clinical Characteristics and Prognosis in Patients with Right- and Left-sided Infective Endocarditis
}

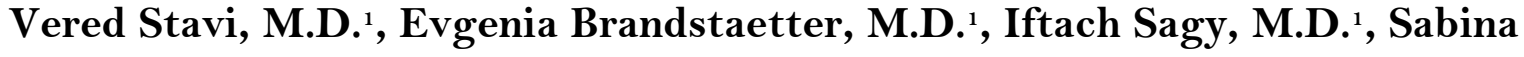 \\ Sapunar, M.D. ${ }^{1}$, Roman Nevzorov, M.D. ${ }^{1}$, Carmi Bartal, M.D. ${ }^{2}$, and Leonid \\ Barski, M.D. ${ }^{*}$ * \\ ${ }^{\prime}$ Department of Internal Medicine F, Soroka University Medical Center, Beer-Sheva, Israel; and \\ ${ }^{2}$ Department of Internal Medicine E, Soroka University Medical Center, Beer-Sheva, Israel
}

\begin{abstract}
Objective: Right-sided endocarditis (RSE) accounts for $5 \%-10 \%$ of all cases of infective endocarditis (IE) and frequently has different etiological, pathogenetic, and clinical presentations compared with left-sided endocarditis (LSE). The aims of this study were to evaluate the epidemiologic and clinical characteristics and prognosis of RSE patients and to compare them with those of LSE patients. This study's importance relates to the local understanding of RSE and LSE, since Israeli demographics are different compared to the Unites States and Europe with regard to intravenous drug abuse and rheumatic valvular disease prevalence.

Material and Methods: A retrospective cohort study of 215 patients with infective endocarditis was performed. The primary outcome was in-hospital mortality. The secondary outcomes were duration of hospitalization, recurrent hospitalization, recurrent infective endocarditis, and one-year mortality.

Results: Of the 215 patients in the study, 176 had LSE and 39 had RSE. The RSE patients were younger than the LSE patients $(48.1 \pm 18.9$ years versus $61.8 \pm 17.0$ years, $P<0.001)$. The most common pathogen in both groups was Staphylococcus aureus, which occurred more in the RSE group (51\%) versus the LSE group (19\%). In-hospital mortality was lower among patients with RSE (2.6\% versus $17 \%, P<0.037)$.
\end{abstract}

\footnotetext{
Abbreviations: CRP, C-reactive protein; IE, infective endocarditis; IVDU, intravenous drug users; LSE, left-sided endocarditis; RSE, right-sided endocarditis; SD, standard deviation; SUMC, Soroka University Medical Center.

Citation: Stavi V, Brandstaetter E, Sagy I, Sapunar S, Nevzorov R, Bartal C, Barski L. Comparison of Clinical Characteristics and Prognosis in Patients with Right- and Left-sided Infective Endocarditis. Rambam Maimonides Med J 2019;10 (1):eooo3. doi:10.5041/RMMJ.10338

Copyright: (C) 2019 Stavi et al. This is an open-access article. All its content, except where otherwise noted, is distributed under the terms of the Creative Commons Attribution License (http://creativecommons.org/licenses/by/3.0), which permits unrestricted use, distribution, and reproduction in any medium, provided the original work is properly cited.
}

Conflict of interest: No potential conflict of interest relevant to this article was reported.

* To whom correspondence should be addressed. E-mail: lbarski@bgu.ac.il 
Conclusions: Our study demonstrated an increasing percentage of RSE compared to LSE among patients with IE. Pacemaker lead infection has become the leading cause of RSE in intravenous drug users (IVDU), although less common in Southern Israel. The etiological and clinical differences between RSE and LSE are noteworthy. Patients with RSE have a better prognosis than those with LSE.

KEY WORDS: Clinical characteristics, etiology, pathogenesis, prognosis, right-sided endocarditis

\section{INTRODUCTION}

Right-sided endocarditis (RSE) accounts for $5 \%-$ $10 \%$ of all cases of infective endocarditis (IE) and most frequently involves the tricuspid valve. ${ }^{1,2}$ Atrisk populations include intravenous drug users (IVDU) and patients who have undergone intravenous catheterization. Other risk factors are alcohol abuse, immunodeficiency, and congenital heart defects. ${ }^{3-7}$

Patients with RSE may be classified into three groups: (1) IVDU; (2) cardiac device carriers; and (3) no left-sided endocarditis (LSE), no IVDU, and no cardiac device. Each group can be considered as independent entities due to the relevant epidemiologic, clinical, microbiological, echocardiographic, and prognostic differences among them. ${ }^{8}$

The most common pathogenic cause of RSE is Staphylococcus aureus, among both IVDU and the rest of the patient population..$^{1,9-13}$ Other RSEcausing pathogens are coagulase-negative staphylococci and Gram-negative bacilli; there are also cases with polymicrobial involvement.9,12,14 The pathogenesis of RSE is unclear. Several mechanisms have been proposed: direct injection of the pathogen into the venous blood stream followed by an encounter with the tricuspid valve, immunological mechanisms, and endothelial injury. ${ }^{15,16}$

The clinical presentation of RSE often involves fever accompanied by respiratory signs and symptoms secondary to septic emboli to the lungs.3,4,17 Due to this unique clinical presentation the diagnosis of RSE is often delayed. ${ }^{18}$ Hence, a strong clinical suspicion must be present in order to establish a diagnosis..$^{18-20}$

The aims of this study were to evaluate the epidemiologic, clinical, and laboratory characteristics of RSE with regard to patients, etiology, and pathogenesis, as compared with LSE, and to evaluate and compare the patient outcomes for RSE versus LSE.

Since Israeli demographics are quite different from those of the Unites States and Europe with regard to intravenous drug abuse and rheumatic valvular disease prevalence, this study has potential importance for the treatment of RSE and LSE patients in Israel.

\section{MATERIALS AND METHODS}

The study focused on IE patients admitted to Soroka University Medical Center (SUMC). The center is the only tertiary hospital for a population of 1.1 million, geographically spread out through an area half the size of the State of Israel.

Institutional Review Board approval was obtained prior initiation of the study. A retrospective cohort study was performed of all adult patients with RSE hospitalized in SUMC between 2003 and 2013, since all medical records were computerized in 2003, making the data easily accessible.

Discharge diagnoses (ICD-9) were used to identify subjects with infective endocarditis according to ICD-9 codes: 112.81, 397, 421.0-421.9, 424, 424.2, 424.9.

All IE cases were reviewed by two investigators (senior physicians in internal medicine) according to the modified Duke criteria for IE diagnosis. ${ }^{20}$

The patients' demographic characteristics, ICD-9 diagnoses, medications, and clinical and laboratory data were obtained from a comprehensive medical chart review and from the computerized hospital database.

Patients with RSE were compared to patients with LSE. In-hospital mortality (primary outcome), duration of hospitalization, recurrent hospitalization, recurrent infective endocarditis, and one-year mortality (secondary outcomes) were obtained.

Data were expressed as mean \pm standard deviation (SD), median \pm interquartile range (IQR), or number and percentage. Comparison of RSE and LSE patient characteristics was performed using $t$ test, chi-square, and non-parametric tests. Survival curves were calculated by the Kaplan-Meier method, and comparison between patient groups was per- 
formed by log-rank test. A two-sided $P$ value $<0.05$ was considered as statistically significant.

\section{RESULTS}

The study included 215 patients diagnosed with IE based on the modified Duke criteria. Of these, 176 had LSE and 39 had RSE.

Patient demographic and clinical characteristics are detailed in Table 1 . The majority of patients were male (total of 132 men and 44 women across both groups). The percentage of men and women in both groups was similar. Patients with RSE were younger than patients with LSE (48.1 \pm 18.9 years versus $61.8 \pm 17.0$ years, $P<0.001)$.

Among the RSE patients there were more IVDU (43.6\% versus $4.0 \%, P<0.001$ ) and more patients with a prior IE episode (15.4\% versus $2.8 \%, P=$ o.006). More LSE patients suffered from cardiac arrhythmia ( $38.6 \%$ versus $20.8 \%, P<0.04$ ), whereas more RSE patients suffered from chronic liver diseases $(17.9 \%$ versus $1.7 \%, P<0.001)$.

There were no statistically significant differences between the two groups in most laboratory parameters, except for an elevated C-reactive protein (CRP) in the RSE group (17 [IQR 6;32] $\mathrm{mg} / \mathrm{L}$ versus 7.3 $[4.7 ; 11.5] \mathrm{mg} / \mathrm{L}, P<0.008)$.

With regard to the reason for hospital admission, more RSE patients were admitted due to an infected pacemaker pocket $(5.1 \%$ versus none, $P=0.03)$. However, there were more cases of inflammatory reactions after cardiac device, prosthetic valve, and grafts in the LSE group (36.4\% versus $15.4 \%$, $P=0.01$ ).

The etiologic factors for RSE and LSE are presented in Table 2. The most common pathogen in both groups was Staphylococcus aureus, which occurred in more than half of the RSE group (51\%) as compared to the LSE group (19\%).

There were no statistically significant differences in the pathologic findings of either group on transesophageal echocardiography (Table 3).

In-hospital mortality rates were lower among patients with RSE (2.6\% versus $17 \%, P<0.037$ ), as shown in Figure 1 and Table 4. There were no statistically significant differences in other outcomes between the two groups of patients. One-year survival curves for RSE and LSE are shown in Figure 2.

\section{DISCUSSION}

Right-sided endocarditis is less common than LSE. In this study, $18.1 \%$ of patients with IE presented with RSE, which was comparable to historical data. ${ }^{1,2}$ However, RSE is common among IVDU; $86 \%$ of IE cases among IVDU present with RSE. ${ }^{21}$ In our study $70 \%$ of RSE patients and $4 \%$ of LSE patients were IVDU. Another significant source of RSE is a pacemaker lead infection. In our study a significant number of patients had had a cardiac or another surgical intervention. Our data confirmed that pacemaker lead infection has become a significant risk factor for IE and specifically for RSE.

According to a previous publication, RSE patients are younger as compared to LSE patients. ${ }^{22}$ Our study confirmed this finding. The higher percentage of RSE patients with recurrent endocarditis as compared to the LSE group is probably due to the increased prevalence of IVDU in the former population.

The pathogeneses of RSE and LSE are known to be different. ${ }^{15,16}$ The literature describes several pathogenetic mechanisms that differentiate between the two types of IE: not only the primary contact of the injected substance with the tricuspid valve in RSE, but also intimal damage and thrombus formation, cocaine-induced endothelial damage with secondary pulmonary hypertension, valvular damage and infection, pressure gradient and turbulence,,$^{15,22,23}$ changes in the valvular endothelium, ${ }^{24}$ and different cytokine expression. ${ }^{25}$ In our study, RSE patients had a significantly more prominent CRP elevation. Elevations of CRP occur in association with acute and chronic inflammation due to a range of causes, including infectious diseases and non-infectious inflammatory disorders. Markedly elevated CRP levels are strongly associated with bacterial infection. ${ }^{26}$ Acute inflammation generally shows a marked CRP response, while low-grade inflammation shows only a minor CRP elevation. The inflammatory response to infection and tissue injury supports host defense, clearance of necrotic tissue, adaptation, and repair, while the purpose of low-grade inflammation appears to be restoration of metabolic homeostasis. ${ }^{27}$ The increased CRP levels found in RSE patients in our study may be due to their young age, resulting in a more prominent inflammatory response, and the respiratory injury, particularly pulmonary parenchyma, often seen in RSE patients as compared to LSE patients. This requires further investigation and research. 
Table 1. Comparison of Epidemiologic, Clinical, and Laboratory Characteristics of Patients with Left- and Rightsided Endocarditis.

\begin{tabular}{|c|c|c|c|}
\hline Parameters & $\begin{array}{c}\text { Right-sided } \\
\text { Endocarditis } \\
n=39\end{array}$ & $\begin{array}{c}\text { Left-sided } \\
\text { Endocarditis } \\
n=176\end{array}$ & $P$ value \\
\hline Age, mean $\pm S D$ & $48.1 \pm 18.9$ & $61.8 \pm 17.0$ & $<0.001$ \\
\hline Male sex, $n(\%)$ & $28(71.8)$ & $104(59.1)$ & 0.1 \\
\hline IV drug user, $n(\%)$ & $17(43.6)$ & $7(4.0)$ & $<0.001$ \\
\hline Endocarditis in the past, $n(\%)$ & $6(15.4)$ & $5(2.8)$ & 0.006 \\
\hline Cardiac pacemaker, $n$ (\%) & $8(20.5)$ & $23(13.1)$ & 0.3 \\
\hline $\begin{array}{l}\text { Inflammatory reaction after cardiac device, } \\
\text { prosthetic valve, and graft, } n(\%)\end{array}$ & $6(15.4)$ & $64(36.4)$ & 0.01 \\
\hline Congestive heart failure, $n(\%)$ & $6(15.4)$ & $27(15.3)$ & 1 \\
\hline Diabetes mellitus, $n$ (\%) & 7 (17.9) & $50(28.4)$ & 0.2 \\
\hline Malignancy, $n(\%)$ & $8(20.5)$ & $22(12.5)$ & 0.5 \\
\hline Chronic pulmonary disease, $n$ (\%) & $1(2.6)$ & $20(11.4)$ & 0.1 \\
\hline Connective tissue disease, $n(\%)$ & none & $6(3.4)$ & 0.5 \\
\hline Chronic liver disease, $n(\%)$ & 7 (17.9) & $3(1.7)$ & $<0.001$ \\
\hline Cardiac arrhythmias, $n(\%)$ & $8(20.8)$ & $68(38.6)$ & 0.04 \\
\hline Rheumatic heart disease & $3(7.7)$ & $33(18.8)$ & 0.1 \\
\hline Rheumatoid factor (IU/mL), median (IQR) & $17(11 ; 68)$ & $35(12 ; 90)$ & 0.09 \\
\hline C-reactive protein (mg/L), median (IQR) & $17(6 ; 32)$ & $7.3(4.7 ; 11.5)$ & 0.008 \\
\hline C3 (mg\%), median (IQR) & $116(76 ; 140)$ & $129(105 ; 146)$ & 0.4 \\
\hline C4 (mg\%), median (IQR) & $26(12 ; 28)$ & $29(23 ; 35)$ & 0.09 \\
\hline Surgery, $n(\%)$ & $9(23.1)$ & $47(26.8)$ & 0.7 \\
\hline \multicolumn{4}{|l|}{ Type of Surgery } \\
\hline AVR, $n(\%)$ & none & $16(9.1)$ & 0.04 \\
\hline MVR, $n(\%)$ & none & $17(9.7)$ & 0.04 \\
\hline Pacemaker lead extraction, $n$ (\%) & $3(7.7)$ & $7(4.0)$ & 0.3 \\
\hline Pacemaker extraction, $n$ (\%) & $1(2.6)$ & $2(1.1)$ & 0.4 \\
\hline TVR/tricuspid valve excision, $n(\%)$ & $2(5.1)$ & none & 0.03 \\
\hline Triple valve surgery (AVR+MVR+TVR), $n$ (\%) & $1(2.6)$ & $1(0.6)$ & 0.3 \\
\hline Double valve surgery (AVR+MVR), $n$ (\%) & none & $3(1.7)$ & 1 \\
\hline Double valve surgery (MVR+TVR), $n$ (\%) & none & $1(0.6)$ & 1 \\
\hline \multicolumn{4}{|l|}{ Main Cause of Admission } \\
\hline Fever, $n(\%)$ & $27(69.2)$ & $115(65.3)$ & 0.7 \\
\hline Chest pain, $n(\%)$ & $2(5.1)$ & $4(2.3)$ & 0.3 \\
\hline Heart failure, $n(\%)$ & $3(7.7)$ & $12(6.8)$ & 0.7 \\
\hline Weakness, anemia, $n(\%)$ & none & $9(5.1)$ & 0.4 \\
\hline Stroke, $n(\%)$ & none & $7(4.0)$ & 0.4 \\
\hline Abnormal echocardiography, $n$ (\%) & none & $7(4.0)$ & 0.4 \\
\hline Infected pacemaker pocket, $n$ (\%) & $2(5.1)$ & none & 0.03 \\
\hline Weight loss, $n(\%)$ & none & $4(2.3)$ & 1 \\
\hline Cough and hemoptysis, $n$ (\%) & $1(2.6)$ & $1(0.6)$ & 0.3 \\
\hline Other, $n(\%)$ & $4(10.3)$ & $15(8.5)$ & 0.8 \\
\hline
\end{tabular}

AVR, aortic valve replacement; IV, intravenous; IQR, interquartile range; MVR, multiple valve replacement; SD, standard deviation; TVR, tricuspid valve replacement. 
It is not surprising that for RSE patients, the majority of whom are IVDU, the percentage of patients with chronic liver diseases is higher, perhaps reflecting the higher rates of hepatitis $B$ and hepatitis $\mathrm{C}$ infections and alcohol abuse in this population.

The most common pathogen in both groups of patients in our study was Staphylococcus aureus, consistent with previous data., ${ }^{1,9,12,28}$ It was found in more than half of the RSE group, as compared to less than $20 \%$ in the LSE group. The absence of coagulase-negative staphylococci in the RSE group was also notable in our study. These etiologic differences are important for management of patients with IE in our region.

The in-hospital mortality in our study was significantly lower in RSE patients as compared to LSE patients. One-year mortality was also lower in RSE

Table 2. Etiologic Factors of Left- and Right-sided Endocarditis.

\begin{tabular}{|l|c|c|c|}
\hline Etiology & $\begin{array}{c}\text { Right-sided } \\
\text { Endocarditis } \\
n=39\end{array}$ & $\begin{array}{c}\text { Left-sided } \\
\text { Endocarditis } \\
n=176\end{array}$ & $P$ value \\
\hline Staphylococcus aureus, $n$ (\%) & $20(51.3)$ & $33(18.8)$ & $<0.001$ \\
\hline Staphylococci, coagulase-negative, $n$ (\%) & none & $24(13.6)$ & 0.009 \\
Streptococci, viridans, $n$ (\%) & $4(10.3)$ & $26(14.8)$ & 0.6 \\
Streptococci, other types, $n$ (\%) & $3(7.7)$ & $13(7.4)$ & 1 \\
HACEK group, $n$ (\%) & none & $8(4.5)$ & 0.3 \\
Gram-negative rods, $n$ (\%) & $2(5.1)$ & $4(2.3)$ & 0.3 \\
Enterococcus, $n$ (\%) & $1(2.6)$ & $23(13.1)$ & 0.08 \\
Fungi, $n$ (\%) & $1(2.6)$ & $2(1.1)$ & 0.4 \\
Pseudomonas, $n$ (\%) & none & $4(2.3)$ & 1 \\
Brucella, $n$ (\%) & none & $3(1.7)$ & 1 \\
Q-fever, $n$ (\%) & none & $3(1.7)$ & 1 \\
Unknown pathogen, culture-negative, $n(\%)$ & $8(20.5)$ & $30(17)$ & 0.6 \\
\hline
\end{tabular}

HACEK, Haemophilus aphrophilus, Actinobacillus actinomycetemcomitans, Cardiobacterium hominis, Eikenella corrodens, and Kingella kingae.

Table 3. Echocardiographic Findings on Transesophageal Echocardiography.

\begin{tabular}{|l|c|c|c|}
\hline Echocardiographic Findings & $\begin{array}{c}\text { Right-sided } \\
\text { Endocarditis } \\
n=39\end{array}$ & $\begin{array}{c}\text { Left-sided } \\
\text { Endocarditis } \\
n=176\end{array}$ & $P$ value \\
\hline Vegetation, $n(\%)$ & $23(59)$ & $99(56.3)$ & 0.8 \\
Abscess, $n(\%)$ & $1(2.6)$ & $2(1.1)$ & 0.4 \\
Mass attached to electrode of the pacemaker, $n(\%)$ & $2(5.1)$ & $8(4.5)$ & 1 \\
New severe valvular insufficiency, $n(\%)$ & $1(2.6)$ & $4(2.3)$ & 1 \\
Prosthetic valve dehiscence, $n(\%)$ & none & $1(.6)$ & 1 \\
Absence of findings typical for endocarditis, $n(\%)$ & $12(30.8)$ & $61(34.7)$ & 0.7 \\
\hline
\end{tabular}


Table 4. Outcomes of Patients with Left- and Right-sided Endocarditis.

\begin{tabular}{|lcc|c|}
\hline Parameters & $\begin{array}{c}\text { Right-sided } \\
\text { Endocarditis } \\
n=39\end{array}$ & $\begin{array}{c}\text { Left-sided } \\
\text { Endocarditis } \\
n=176\end{array}$ & $P$ value \\
\hline Recurrences of endocarditis, $n(\%)$ & $4(10.3)$ & $20(11.4)$ & 1 \\
Recurrent hospitalization, $n(\%)$ & $5(12.5)$ & $17(9.7)$ & 0.5 \\
In-hospital mortality, $n(\%)$ & $1(2.6)$ & $30(17)$ & 0.037 \\
One-year mortality, $n(\%)$ & $2(5.1)$ & $22(12.5)$ & 0.2 \\
Length of hospital stay, median (IQR) & $31(18 ; 45)$ & $27(15 ; 42)$ & 0.08 \\
\hline
\end{tabular}

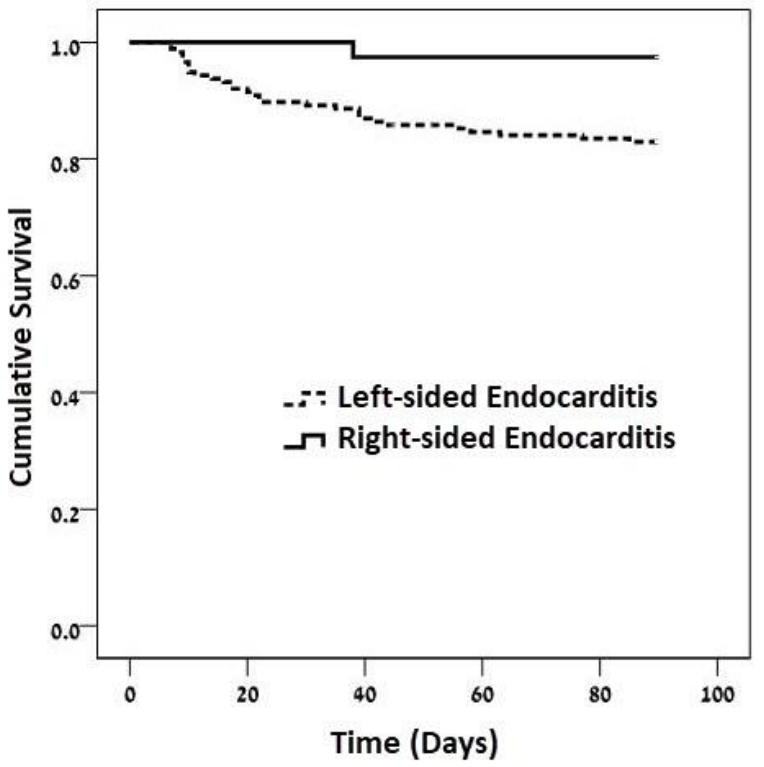

Figure 1. Kaplan-Meier In-hospital Survival Curves Stratified by Endocarditis with Left- and Right-side Involvement.

Log-rank test $P=0.023$.

groups compared to LSE groups, but did not reach statistical significance. These results are also similar to previous studies. ${ }^{29}$ It is known that the prognosis of RSE is better than for LSE, possibly due to the younger age of the RSE patients, and tricuspid valve involvement has few hemodynamic consequences compared to mitral valve dysfunction. ${ }^{22,29}$ The majority of RSE patients responded well to appropriate antibiotic therapy without complications and with no spread beyond the borders of the involved valve. ${ }^{30,31}$ Very few RSE patients need operative treatment of the involved valve..$^{21,32-34}$ In our study only a minority of patients in both groups required operative treatment.

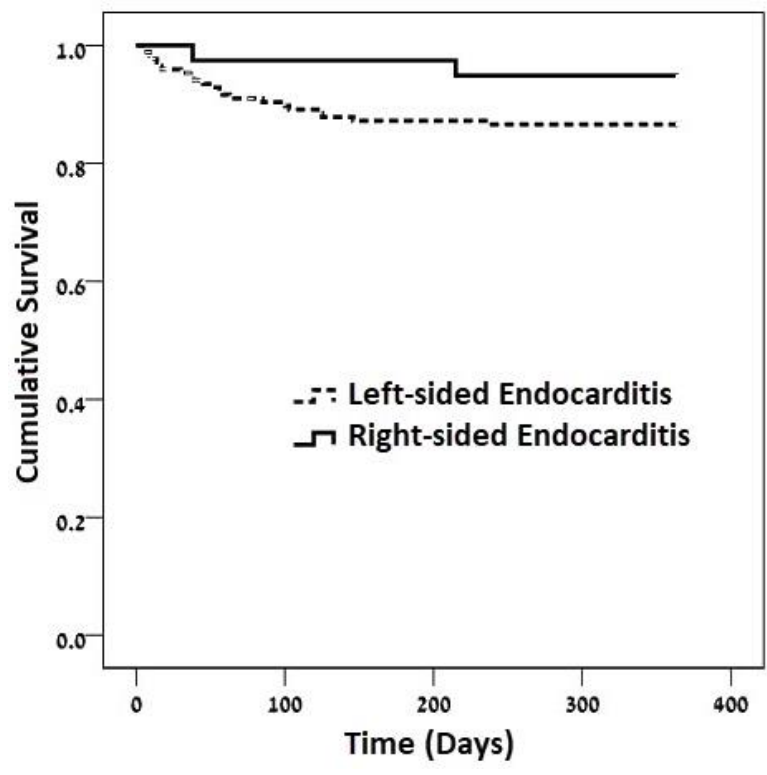

Figure 2. Kaplan-Meier One-year Survival Curves Stratified by Endocarditis with Left- and Right-side Involvement.

Log-rank test $P=0.015$.

The results of this study have demonstrated a difference in the characteristics of RSE patients in our study versus previous studies, i.e. a documented higher percentage of patients with pacemaker lead infection and fewer who were IVDU. Indeed, intravenous drug abuse in Israel is less common. Pacemaker lead infection is the leading cause of RSE in Southern Israel. Due to the increased use of these devices, a high index of suspicion is needed so as to diagnose RSE at-risk patients with appropriate clinical presentations.

Another interesting finding of our study was that a mass attached to the electrode was just as common 
in LSE, indicating that sometimes left- and rightsided endocarditis can occur simultaneously.

The major limitations of this study are that it was a single-center investigation and that it used ICD codes to identify patients. However, patients were analyzed over a 10-year period.

\section{CONCLUSION}

Our study demonstrated an increasing percentage of RSE compared to LSE among patients with IE in Southern Israel. This trend is expected to continue due to the increasing number of patients undergoing device insertion. Pacemaker lead infection has become the leading cause of RSE in Southern Israel; it is much less common to find RSE in IVDU. This study has also demonstrated etiological and clinical differences between RSE and LSE, with the RSE prognosis being better compared to LSE.

\section{REFERENCES}

1. Frontera JA, Gradon JD. Right-side endocarditis in injection drug users: review of proposed mechanisms of pathogenesis. Clin Infect Dis 2000;30:374-9. Crossref

2. Chan P, Ogilby JD, Segal B. Tricuspid valve endocarditis. Am Heart J 1989;117:1140-6. Crossref

3. Naidoo DP. Right-sided endocarditis in the non-drug addict. Postgrad Med J 1993;69:615-20. Crossref

4. Nandakumar R, Raju G. Isolated tricuspid valve endocarditis in nonaddicted patients: a diagnostic challenge. Am J Med Sci 1997;314:207-12.

5. Clifford CP, Eykyn SJ, Oakley CM. Staphylococcal tricuspid valve endocarditis in patients with structurally normal hearts and no evidence of narcotic abuse. QJM 1994;87:755-7.

6. Yamashita S, Noma K, Kuwata G, Miyoshi K, Honaga $\mathrm{K}$. Infective endocarditis at the tricuspid valve following central venous catheterization. J Anesth 2005; 19:84-7. $\underline{\text { Crossref }}$

7. Michel PL, Acar J. Native cardiac disease predisposing to infective endocarditis. Eur Heart J 1995; 16(Suppl B):2-6.

8. Ortiz C, López J, García H, et al. Clinical classification and prognosis of isolated right-sided infective endocarditis. Medicine (Baltimore) 2014;93:e137. Crossref

9. Revilla A, López J, Villacorta E, et al. Isolated rightsided valvular endocarditis in non-intravenous drug users. Rev Esp Cardiol 2008;61:1253-9.
10. Cremieux AC, Witchitz S, Malergue MC, et al. Clinical and echocardiographic observations in pulmonary valve endocarditis. Am Cardiol 1985;56:610-13. Crossref

11. Murdoch DR, Corey GR, Hoen B, et al.; International Collaboration on Endocarditis-Prospective Cohort Study (ICE-PCS) Investigators. Clinical presentation, etiology, and outcome of infective endocarditis in the 21st century: the International Collaboration on Endocarditis-Prospective Cohort Study. Arch Intern Med 2009;169:463-73. Crossref

12. Haque NZ, Davis SL, Manierski CL, et al. Infective endocarditis caused by USA30o methicillin-resistant Staphylococcus aureus (MRSA). Int J Antimicrob Agents 2007;30:72-7. Crossref

13. Saydain G, Singh J, Dalal B, Yoo W, Levine DP. Outcome of patients with injection drug use-associated endocarditis admitted to an intensive care unit. J Crit Care 2010;25:248-53. Crossref

14. Chambers HF, Morris DL, Täuber MG, Modin G. Cocaine use and the risk for endocarditis in intravenous drug users. Ann Intern Med 1987:106;833-6. Crossref

15. Stein M. Medical complications of 1 intravenous drug use. J Gen Intern Med 1990;5:249-57.

16. Mouhaffel AH, Madu EC, Satmary WA, Fraker TD Jr. Cardiovascular complications of cocaine. Chest 1995; 107:1426-34. Crossref

17. Muthukumaran CS, Govindaraj PR, Vettukattil J. Testicular swelling with pneumonia and septicaemia: a rare presentation of right-sided endocarditis. Cardiol Young 2005;15:532-3. Crossref

18. Chahoud J, Sharif Yakan A, Saad H, Kanj SS. Rightsided infective endocarditis and pulmonary infiltrates: an update. Cardiol Rev 2016;24:230-7. $\underline{\text { Crossref }}$

19. Bonow RO, Carabello BA, Chatterjee K, et al. 2008 Focused update incorporated into the ACC/AHA 2006 guidelines for the management of patients with valvular heart disease: a report of the American College of Cardiology/American Heart Association Task Force on Practice Guidelines (Writing Committee to Revise the 1998 Guidelines for the Management of Patients With Valvular Heart Disease): endorsed by the Society of Cardiovascular Anesthesiologists, Society for Cardiovascular Angiography and Interventions, and Society of Thoracic Surgeons. Circulation 2008; 118:e523-661. $\underline{\text { Crossref }}$

20. Li JS, Sexton DJ, Mick N, et al. Proposed modifications to the Duke criteria for the diagnosis of infective endocarditis. Clin Infect Dis 2000;30:633-8. Crossref

21. Levine D, Crane LR, Zervos MJ. Bacteremia in narcotic addicts at the Detroit Medical Center. II. Infec- 
tious endocarditis: a prospective comparative study. Rev Infect Dis 1986;8:374-96.

22. Welton DE, Young JB, Gentry WO, et al. Recurrent infective endocarditis: analysis of predisposing factors and clinical features. Am J Med 1979;66:932-8. Crossref

23. Kauffmann RH, Thompson J, Valentijn RM, Daha MR, Van Es LA. The clinical implications and the pathogenetic significance of circulating immune complexes in infective endocarditis. Am J Med 1981; 71:17-25. Crossref

24. Sullam PM, Drake TA, Sande MA. Pathogenesis of endocarditis. Am J Med 1985;78;110-15. Crossref

25. Husby G, Pierce PE, Williams RC. Smooth muscle antibody in heroin addicts. Ann Intern Med 1975; 83;801-5. Crossref

26. Volanakis JE. Human C-reactive protein: expression, structure, and function. Mol Immunol 2001;38:18997. Crossref

27. Chovatiya R, Medzhitov R. Stress, inflammation, and defense of homeostasis. Mol Cell 2014;54:2812. $\underline{\text { Crossref }}$

28. Hecht SR, Berger M. Right-sided endocarditis in intravenous drug users. Prognostic features in 102 episodes. Ann Intern Med 1992;117:560-6. $\underline{\text { Crossref }}$
29. Kamaledeen A, Young C, Attia RQ. What are the differences in outcomes between right-sided active infective endocarditis with and without left-sided infection? Interact Cardiovasc Thorac Surg 2012; 14:205-8. Crossref

30. Robbins MJ, Frater RW, Soeiro R, Frishman WH, Strom JA. Influence of vegetation size on clinical outcome of right-sided infective endocarditis. Am J Med 1986;80:165-71. $\underline{\text { Crossref }}$

31. Miro JM, del Rio A, Mestres CA. Infective endocarditis and cardiac surgery in intravenous drug abusers and HIV-1 infected patients. Cardiol Clin 2003;21:167-84. Crossref

32. Akinosoglou K, Apostolakis E, Marangos M, Pasvol G. Native valve right sided infective endocarditis. Eur J Intern Med 2013;24:510-19.

33. Vallabhajosyula S, Varma MD, Vallabhajosyula S, Vallabhajosyula S. Right-sided infective endocarditis in an Indian intensive care unit. J Glob Infect Dis 2016;8:124-5. $\underline{\text { Crossref }}$

34. Lee MR, Chang SA, Choi SH, et al. Clinical features of right-sided infective endocarditis occurring in nondrug users. J Korean Med Sci 2014;29:776-81. Crossref 